\title{
Hypertrophy and Hyperplasia
}

National Cancer Institute

\section{Source}

National Cancer Institute. Hypertrophy and Hyperplasia. NCI Thesaurus. Code C120891.

A finding of both hypertrophy and hyperplasia in the same lesion. 